\title{
Cultural Bias in Standard Tests of Mental Abilities
}

Judith K. Bernhard

Ryerson University

digital.library.ryerson.ca/object/348

Please Cite:

Bernhard, J. K. (1992). Cultural bias in standard tests of mental abilities. Multiculturalism, 14(2/3), 53-55.

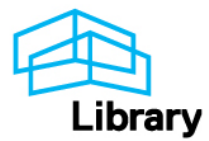




\title{
Cultural Bias in Standard Tests of Mental Abilities
}

\author{
Judith K. Bernhard, School of Early Childhood Education, Ryerson Polytechnical Institute, Toronto
}

Cet article présente les dangers $d^{\prime}$ utilisation de tests d'aptitudes mentales pour les enfants de cultures différentes, et des implications qui en découlent pour les éducateurs de jeunes enfants.

Despite calls for equity ${ }^{1}$ and freedom from bias in education, the goal of fair outcomes has proven to be elusive. In a 1987 policy statement, the Ontario Ministry of Education focused on the issue of fair treatment of all students and the dangers of culturally biased tests, but the problem continues. In major Canadian cities, school dropout rates among certain minority groups of both white and non-white races continue to be disproportionately high (Mackay and Myles, 1989; Radwansky, 1988; Wright and Tsuji, 1984). The low aspirations and expectations of these groups also reflect inequitable school experiences. Attitudes about one's self, one's abilities, and one's future are formed in the earliest years of school, and persist and are reinforced in later primary and secondary education. Early childhood educators would do well to become aware of the ways in which some well-known and standard educational assessment tools contribute to bias in the educational process.

In addition to IQ tests, tests of general scholastic aptitude or academic proficiency all rest on problematic assumptions about human abilities:

1. that there exists a single overall entity, intellectual capacity, or general mental ability (the famous $g$ factor of Spearman, 1927);

2. that this capacity is the main determinant of academic success (e.g., Jensen, 1969, 1980; Terman and Oden, 1959);

3. that the capacity is (or can be) measured by standard tests;

4. that the tests can be purged of cultural bias by careful design.

All these assumptions need to be critically examined, and I would argue that if assumptions one and three are false, then these tests are fundamentally defective. Any use of these tests in the assessment and placement of culturally-diverse students in particular

${ }^{1}$ The term equity is used throughout this paper as meaning fairness, a broader concept than that of equality. becomes problematic, and biased outcomes become almost inevitable. Let's examine the assumptions one by one.

Assumption One. Is there, in fact, a unitary intellectual capacity? Prominent theorists have argued against the existence of such a single entity. Cattell and Horn (Cattell, 1959; Horn and Cattell, 1967) proposed two types of intelligence: fluid and crystalized. Thorndike (1927) thought of intelligence as being composed of several independent elements, each representing different abilities. Gardner (1983) has outlined a theory of "multiple intelligences," including mathematical, artistic, and interpersonal intelligence. Still others have argued that there is no one capacity, intelligence, but rather many particular mental abilities (e.g., Guilford, 1985). Although the early oneor two-factor theories have provided the conceptual base for many measures of mental ability (e.g., Stanford-Binet, WISC-R), the arguments against a unitary conception of intelligence have been well documented.

Assumption Two. What is the relationship between intelligence tests and school success? There are strong positive correlations; IQ tests do predict academic success. Nonetheless, we may still question whether intelligence, as measured, is the main cause of such success. McClelland (1976) has argued that intelligence tests also correlate well with factors such as socio-economic status and parental aspirations. Nevertheless, these correlations cannot be interpreted to mean that parental aspirations are ability factors (see also Wiener, Weizmann, Wiesenthal, and Ziegler, 1990). McClelland further argues that "neither the tests nor school grades seem to have much power to predict real competence in many life outcomes, aside from the advantages that credentials convey on the individuals concerned" (p. 56).

Assumption Three. Is intelligence measured by the standard tests? For psychologists, this is the question of construct validity: does a psychological test measure what it claims to measure? If the first assumption is false, and there is no unitary capacity that could be measured, then the third assumption is also false: if there is no unitary intelligence, then no standardized test does (or could) really measure it. But what are the actual arguments of psychologists 
that unitary intelligence is truly being measured? They have emphasized the strong correlations of test items with each other and with the test as a whole. However, it has been assumed that the individual items all measure the same thing, and items have been excluded that were not thought to represent intellectual ability. Obviously this is a circular argument: first, because the term "intellectual ability" is used to mean whatever is being measured by the test; second, because of the arbitrary exclusion of certain items claimed not to be representative.

Assumption Four. How successful have the attempts been to develop culture-free tests by redesigning them? Various approaches have been tried: eliminating certain questions, broadening the standardization sample, and using language-free geometrical or numeric tests. Critiques of cultural fairness in IQ tests have been developed (e.g., Cummins, 1984; Samuda, 1975).

In using these tests, some have argued that a more sophisticated use of the test or revised procedures for scoring might be sufficient. For example, Mercer and Lewis (1979) attempted to revise Wechsler Intelligence Scale for Children (WISC) scores based on medical, social, and pluralistic information. If, as already argued, the tests are fundamentally defective, then deriving more sophisticated ways of interpreting the scores does not seem to be the best approach to valid educational decision-making.

\section{Principles}

To reach equitable outcomes, assessment and teaching procedures need to be based on sound educational principles. The following are offered as preliminary guidelines. First, all assessment must be within a person's own cultural framework and context. Rather than searching for culture-free tests, we want to tap basic abilities to think and adapt that are considered important in that culture.

A second principle is that the test scores must not reflect the state of performance at a particular time, but the improvement of performance in a proper teaching and learning context. This idea is summed up in the slogan "test-teach-test" of Feuerstein (1979).

\section{Alternatives}

Vygotsky $(1978,1962)$ proposed the concept of a Zone of Proximal Development, and many educators have based assessment approaches on this concept (Brown and Ferrara, 1985; Budoff, 1987; Burns, Vye, Bransford, Delclos, and Ogan, 1987; Gamlin, 1990). The Zone of Proximal Development is the gap between current performance and the performance that could be readily achieved through proper instruction and experience. For example, Feuerstein's 1979
Learning Potential Assessment Device (LPAD) employs a test-teach-test model to assess learning potential. In contrast to conventional assessment procedures which attempt to assess what the student knows, Feuerstein advocates inferring learning potential on the basis of direct assessment of learning in the assessment situation. In his model, intelligence is defined as "the capacity of an individual to use previously acquired experiences to adjust to new situations. The two factors stressed in this definition are the capacity of the individual to be modified by learning and the ability of the individual to use whatever modification has occurred for future adjustments" (1979, p. 76).

The goals of the LPAD are (a) to identify existing cognitive functions; (b) to evaluate the type and degree of intervention required to overcome deficiencies; and (c) to assess the child's level of modifiability, or responsiveness to particular interventions (Feuerstein, Haywood, Rand and Hoffman, 1986). The examiner is not neutral, but rather acts as a mediator in order to bring out the child's potential under ideal conditions. In spite of obstacles such as the large amount of time required for assessment and the extensive training required to administer the LPAD effectively, dynamic assessment is a promising alternative because it provides valuable information about optimal strategies and approaches for specific students. The validity of the LPAD needs further demonstration; for a critique, see Missiuna and Samuels (1988).

\section{Empowerment Pedagogy}

While the abolition of standardized testing may sound utopian, Cummins (1989) describes several projects based on alternative models of pedagogy: the Descubrimiento Program in New Jersey (DeAvila, Cohen, and Intili, 1981); the Pajaro Valley Family Literacy Experience (Ada, 1988); and the Orillas Project in Connecticut (Sayers, 1986). These programs are all based on empowerment pedagogy and community involvement, and their results are worth further investigation. The goals of these projects are to alleviate the educational difficulties of minority students by taking advantage of the intellectual and cultural resources within the community for promoting the academic development of minority children.

\section{Conclusion}

There is a link between assessment procedures and cultural inequities in the school system. Inequities result because testing procedures are based on a defective concept, that of a culture-free intellectual ability. Educators need to recognize a diversity of mental abilities and skills, as well as an appreciation of their relationship to cultural context. New ap- 
proaches to assessment and pedagogy must honour diversity and move in the direction of dynamic assessment. A dynamic, culture-bound approach, along with general improvement of the social position of minority students and of their parents, will help bring about equitable educational outcomes and foster optimal personal development of those from various ethnic and cultural backgrounds.

\section{References}

Ada, A.F. "The Pajaro Valley experience: Working with Spanishenglish parents to develop children's reading and writing skills in the home through the use of children's literature," In T. Skutnabb-Kangas and J. Cummins, eds. Minority education: From shame to struggle. Clevedon, England: Multilingual Matters, 1988.

Brown, A.L., and Ferrara, R.A. 'Diagnosing zones of proximal development." In: J. Wersch, ed. Culture, communication, and cognition: Vygotskian perspectives. Cambridge, MA: Cambridge University Press, 1985.

Budoff, M. "Measures of assessing learning potential." In: C.S. Lidz, ed. Dynamic assessment. New York: Guilford Press, 1987: 173-95.

Burns, M.S., Vye, N.J., Bransford, J.D., Delclos, V.R., and Ogan, T. "Static dynamic measures of learning in young handicapped children." Diagnostique (12), 1987: 59-73.

Cattell, R. Handbook for the Culture-Fair Intelligence Test: A measure of " $g$ ". Champaign, Illinois: Institute for Personality and Ability Testing, 1959 .

Cummins, J. Bilingual and special education: Issues in assessment and pedagogy. Clevedon, England: Multilingual Matters, 1984.

Cummins, J. Empowering minority students. Sacramento, CA: California Association for Bilingual Education, 1989.

DeAvila, E.A., Cohen, E.G., Intili, J.A. Multicultural improvement of cognitive abilities. Final report to California State Department of Education, 1981.

Feuerstein, R. The dynamic assessment of retarded performers: the learning potential assessment device, theory, instruments, and techniques. Baltimore, MD: University Park Press, 1979

Gamlin, P.J. "Promoting the generalization of knowledge: A developmental approach to teaching metaphorical thinking." Canadian Journal of Special Education (23), 1990: 101-13.

Gardner, H. Frames of mind: The theory of multiple intelligences. New York: Basic Books, 1983.
Guilford, J.P. "The structure of intellect model." In: B.B. Wolman, ed. Handbook of intelligence: Theories, measurements, and applications. New York: John Wily \& Sons, Inc., 1985.

Horn, J.L., Cattell, R.B. "Age differences in fluid and crystallized intelligence." Acta Psychologia. (26), 1967: 107-29.

Jensen, A.R. "How much can we boost IQ and scholastic achievement?" Harvard Educational Review (39), 1969: 1-123.

Jensen, A.R. Bias in mental testing. New York: The Free Press. MacMillan Publishing Co., 1980.

Mackay, R., Myles, L. Native student dropouts in Ontario Toronto: Ministry of Education, 1989.

McClelland, D.C. "Testing for competence rather than for "intelligence"." In: N.J. Block and G. Dworkin, eds. The IQ controversy. New York: Pantheon Books, 1976.

Mercer, J., Lewis, J.F. System of multi-cultural pluralistic assessment (SOMPA). New York: The Psychological Corporation, 1979.

Missiuna, C., Samuels, M. "Dynamic assessment: Review and critique." Special Services in the Schools (5:1/2), 1989: 1-22.

Ontario Ministry of Education. The development of a policy on race, and ethnocultural equity. Report of the Provincial Advisory Committee on Race Relations. September, 1987.

Radwansky, G. Ontario study of the relevance of education, and the issue of dropouts. Toronto: Ministry of Education, 1988.

Samuda, R.J. "From ethnocentrism to a multicultural perspective in educational testing." Journal of Afro-American Issues 3:1, 1975:

Sayers, D. "Sending messages across the classroom and around the world." Computer-Assisted Language Learning. Special Supplement No.3, TESOL Newsletter 20, 1986: 7-8.

Spearman, C. The abilities of man. New York: MacMillan. Terman, L.M., Oden, M. eds. 1927; reprinted, 1959.

Terman, L.M., Oden, M.H. The gifted group at mid-life. Stanford, CA: Stanford University Press, 1959.

Thorndike, E.L. The measurement of intelligence. New York: Bureau of Publications, Teachers' College, Columbia University, 1927.

Vygotsky, L.S. Mind in society: The development of high psychological processes. M. Cole, V.J. Steiner, and E. Souberman, eds. and trans. Cambridge, MA.: Harvard University Press, 1978.

Vygotsky, L.S. Thought and language. Cambridge, MA: M.I.T. Press, 1962 .

Wiener, N., Weizmann, F., Wiesenthal, D., Ziegler, M. "I.Q. economic productivity, and eugenics." International Journal of Dynamic Assessment and Instruction (1:2), 1990: 105-15.

Wright, E.N., Tsuji, G.K. The grade nine student survey: Fall 1983. Toronto: Toronto Board of Education, 1984.

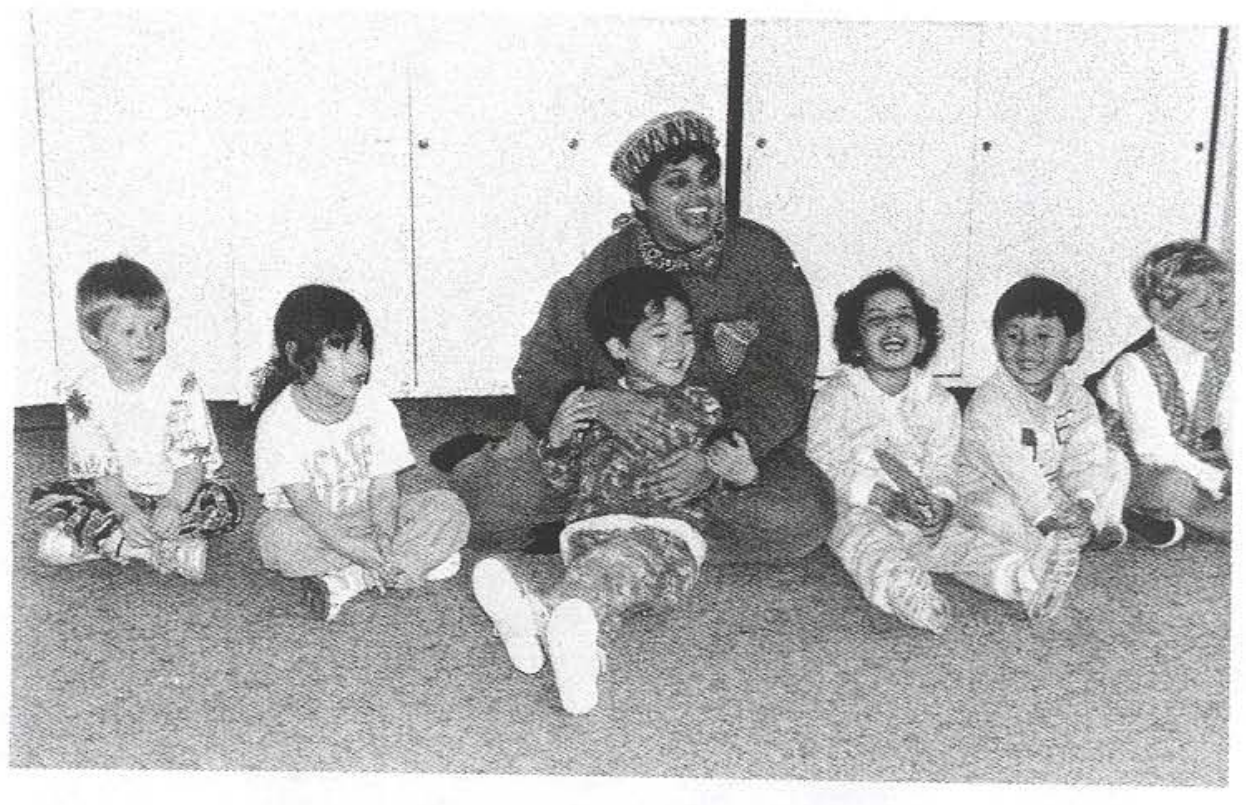

